DOI: https://doi.org/10.36502/2021/ASJBCCR.6239

\title{
Current Perspectives of Periodontal Disease (PD) and Diabetes Mellitus (DM)
}

\author{
Hiroshi Bando ${ }^{1,2^{*}}$ \\ ${ }^{1}$ Medical Research/Tokushima University, Tokushima, Japan \\ ${ }^{2}$ Japan Low Carbohydrate Diet Promotion Association (JLCDPA), Kyoto, Japan
}

Corresponding Author: Hiroshi BANDO, MD, PhD, FACP ${ }^{\text {ORCID iD }}$

Address: Tokushima University /Medical Research, Nakashowa 1-61, Tokushima 770-0943, Japan. Tel: +81-90-31872485. Email: pianomed@bronze.ocn.ne.jp

Received date: 04 May 2021; Accepted date: 30 May 2021; Published date: o8 June 2021

Citation: Bando H. Current Perspectives of Periodontal Disease (PD) and Diabetes Mellitus (DM). Asp Biomed Clin Case Rep. 2021 Jun 08;4(2):107-109.

Copyright (C) 2021 Bando $\mathrm{H}$. This is an open-access article distributed under the Creative Commons Attribution License, which permits unrestricted use, distribution, and reproduction in any medium provided the original work is properly cited.

\begin{abstract}
Combination of diabetes mellitus (DM) and periodontal disease (PD) has been a problem. Diabetic cases with PD showed elevated odds ratio (OR) compared to those without PD, where retinopathy 2.8-8.7, nephropathy 1.9-8.5, neuropathy 3.2-6.6, cardiovascular complications 1.3-17.7, and mortality 2.3-8.5. Medical and dental staffs always manage to check DM and PD.
\end{abstract}

\section{Keywords}

Diabetes Mellitus, Periodontal Disease, Odds Ratio, Type 2 DM, Periodontitis

\section{Abbreviations}

DM: Diabetes Mellitus; PD: Periodontal Disease; OR: Odds Ratio; T2DM: Type 2 DM

Diabetes mellitus (DM) has been increasing and highly prevalent worldwide [1]. The association of DM and periodontal disease (PD) has been a problem [2]. $\mathrm{PD}$ has been recognized as the $6^{\text {th }}$ common diabetic complication. Between periodontitis and type $2 \mathrm{DM}$ (T2DM), consistent evidence has been present as a dual directionality [3]. Various clinical problems are caused in diabetic patients with PD [4]. Current trend for DM and PD will be described from several points of view in this article.

For clinical studies, several recent reports were observed. A meta-analysis was performed from 3987 diabetic cases in 8 articles [5]. Mutual association among PD, nephropathy, and retinopathy was studied.
The results showed that $\mathrm{PD}$ has elevated total microvascular complications (odds ratio, OR, 1.96). Furthermore, PD showed higher nephropathy (OR 1.55) and retinopathy (OR 3.77). Thus, $P D$ is proved to be present more in diabetes and larger clinical study will be required in the future.

From a systematic review, the association of PD and diabetic complications was investigated [2]. It analyzed OR from 14 studies concerning micro-/macro-vascular complications. In comparison with DM without PD, diabetic cases with PD showed elevated OR. The results were retinopathy 2.8-8.7, nephropathy 1.9-8.5, neuropathy 3.2-6.6, cardiovascular complications $1.3^{-}$ $17 \cdot 7$, and mortality $2 \cdot 3-8.5$. 


\section{Editorial}

Regarding the combined problem of $\mathrm{DM}$ and $\mathrm{PD}$, dental evaluation and basic analyses are crucial. A recent report showed the analyses of 182 diabetic patients with PD [6]. The protocol included HbA1c, preprandial glucose, the remaining number of teeth, clinical attachment level (CAL), presence of suppuration (SUP), probing depth, bleeding on probing (BoP), and others. As a result, two groups (HbA1c $\geq 7 \%$ vs $\mathrm{HbA1c}<7 \%$ ) revealed a significant difference for markers, which were 18.5 vs 20.4 in remaining teeth, 4.5 vs $4.1 \mathrm{~mm}$ in CAL, 3.78 vs $3.42 \mathrm{~mm}$ in probing depth. Consequently, cases in poor control showed the severer situation of PD than those in better control.

The actual dental condition of PD is important, and it can be evaluated by the application of a Periodontal Inflamed Surface Area (PISA) Index. Using PISA, 104 T2DM cases were investigated [7]. The result showed that an increase of each $10 \mathrm{~mm}^{2}$ of PISA would bring OR of $2 \%$ increase in $\mathrm{HbA1c}$ level. This paper gives evidence-based data for this clinical issue.

From a basic medicine point of view, periodontal pathogens would bring cytokine production and oxidative stress leading to dysfunction of insulin sensitivity [8]. Chronic inflammation of gum around the teeth continues for long, which comes from biofilm accumulation by improper oral hygiene. Biofilm has $>1000$ kinds of microorganisms, such as Porphyromonas Gingivalis, and Tannerella Forsythia, and so on [9]. They contribute to the perpetuation of $\mathrm{PD}$, causing impaired support of periodontal tissue and bone.

In usual clinical practice, patients with DM and PD were often observed. Research for chairside screening for undiagnosed diabetes mellitus (UDM) was conducted $(n=7343)$ [10]. The results showed that UCD was 5.6\%, obesity, and toothless jaw was $12.6 \%$, obesity and PD was $12.2 \%$. From the questionnaire study of PD and hygiene habits, proper oral health education was proved to be required [11]). In summary, medical and dental staffs always keep adequate management of evaluating DM and PD.

\section{Conflict of Interest}

The author has read and approved the final version of the manuscript. The author has no conflicts of interest to declare.

\section{References}

[1] American Diabetes Association. 3. Prevention or Delay of Type 2 Diabetes: Standards of Medical Care in Diabetes-2021. Diabetes Care. 2021 Jan;44(Suppl 1):S34-S39. [PMID: 33298414]

[2] Nguyen ATM, Akhter R, Garde S, Scott C, Twigg SM, Colagiuri S, Ajwani S, Eberhard J. The association of periodontal disease with the complications of diabetes mellitus. A systematic review. Diabetes Res Clin Pract. 2020 Jul;165:108244. [PMID: 32526263]

[3] Wu CZ, Yuan YH, Liu HH, Li SS, Zhang BW, Chen W, An ZJ, Chen SY, Wu YZ, Han B, Li CJ, Li LJ. Epidemiologic relationship between periodontitis and type 2 diabetes mellitus. BMC Oral Health. $2020 \mathrm{Jul}$ 11;20(1):204. [PMID: 32652980]

[4] Sakamoto D, Bando H, Iwatsuki N, Sakamoto K, Okada M, Ogawa T. Remarkable Improvement of Periodontal Diseases (PD) and Diabetic State with Weight Reduction by Super Low Carbohydrate Diet (LCD). Journal of Oral and Dental Health Research. 2020 Jun 29;2(2):114.

[5] Wu HQ, Wei X, Yao JY, Qi JY, Xie HM, Sang AM, Jiang K. Association between retinopathy, nephropathy, and periodontitis in type 2 diabetic patients: a Meta-analysis. Int J Ophthalmol. 2021 Jan 18;14(1):141-47. [PMID: 33469496]

[6] Stoicescu M, Calniceanu H, T,ig I, Nemeth S, Tent A, Popa A, Brisc C, Ignat-Romanul I. Significant aspects and correlation between glycemic control and generalized chronic periodontitis in type 2 diabetes mellitus patients. Exp Ther Med. 2021 Jul;22(1):671. [PMID: 33986836]

[7] Romano F, Perotto S, Mohamed SEO, Bernardi S, Giraudi M, Caropreso P, Mengozzi G, Baima G, Citterio F, Berta GN, Durazzo M, Gruden G, Aimetti M. Bidirectional Association between Metabolic Control in Type-2 Diabetes Mellitus and Periodontitis Inflammatory Burden: A Cross-Sectional Study in an Italian Population. J Clin Med. 2021 Apr 20;10(8):1787. [PMID: 33924022]

[8] Prasad R, Raj A, Khan SF, Agarwal S, Shalini B, HS C. Effect of non-surgical periodontal therapy on glycemic control of patients with chronic periodontitis and type-2 diabetes mellitus: A 3 month follow-up 
Citation: Bando H. Current Perspectives of Periodontal Disease (PD) and Diabetes Mellitus (DM). Asp Biomed Clin Case Rep. 2021 Jun 08;4(2):107-109.

\section{Editorial}

intervention study. Internat J Applied Dental Sci 2021; 7(2): 05-08.

[9] Zaha DC, Bungau S, Uivarosan D, Tit DM, Maghiar TA, Maghiar O, Pantis C, Fratila O, Rus M, Vesa CM. Antibiotic Consumption and Microbiological Epidemiology in Surgery Departments: Results from a Single Study Center. Antibiotics (Basel). 2020 Feb 13;9(2):81. [PMID: 32069828]

[10] Philips KH, Zhang S, Moss K, Ciarrocca K, Beck JD.
Periodontal disease, undiagnosed diabetes, and body mass index: Implications for diabetes screening by dentists. J Am Dent Assoc. 2021 Jan;152(1):25-35. [PMID: 33256949]

[11] Valentim FB, Carneiro VC, Costa Gomes PD, Rosetti EP. The Importance of Integrated Healthcare in the Association Between Oral Health and Awareness of Periodontitis and Diabetes in Type 2 Diabetics. Oral Health Prev Dent. 2021;19(1):1-6. [PMID: 33491372] 